\title{
Demographics for Segmentation in Online Travel
}

\author{
Michael Conyette, BA, MBA, DBA
}

\begin{abstract}
The relationship between various demographics and online leisure travel booking intention was investigated yielding some interesting results. Consequently, this study recommends these demographic variables be considered in segmenting travelers to find those more likely to book online. Spearman correlation analysis and the Kruskal-Wallis test revealed insights on the demographic data that are valuable for targeting leisure travelers in the online marketplace.
\end{abstract}

Index Terms — internet; leisure travel; online; segmentation

\section{INTRODUCTION}

For decades research has been done on segmentation in traditional markets [1]. Market segmentation has traditionally been accomplished using variables such as purchase and usage behavior, psychographics, demographics and geography. Even segmentation based on alternative methods such as lifetime value and long-term profitability yield some useful insights of consumers in these markets [1]. These approaches and combinations of methods may be pertinent in the Internet marketplace.

For example, segmentation using lifetime value of the customer could treat an online consumer as an asset worthy of identifying and targeting for special treatment just as much as an offline consumer. Likewise, alternative measures for segmenting (in an online context) can create multiple views of the same market [1].

Segmentation research on the travel industry specifically is also useful. Reference [2] studied Singapore consumers to find that light users of travel agents exhibited differences from heavy users. This volume segmentation of travelers shows that heavy users were more innovative and knowledgeable, more involved with vacation travel, and they were more likely to be opinion leaders.

Ref. [3] segmented travelers using an International Tourism Role (ITR) scale. Tourist roles are based on the degree to which tourists desire novelty or familiarity in their vacation [4]. The US travel market was segmented according to benefits realized and it is proposed that the best way to understand consumers' motivations for vacation travel or benefits sought from a vacation destination is to study consumers' past travel behavior [5].

However, marketers are beginning to consider the uniqueness of online markets and are conducting research

Michael Conyette, BA, MBA, DBA is Okanagan School of Business Okanagan College Vernon, British Columbia, Canada (e-mail: mconyette@okanagan.bc.ca). specific to the new media. Ref. [6] segmented web shoppers, based on their purchase behavior across several product categories. They then profiled the segments along the twin dimensions of demographics and benefits sought to show that benefits sought can provide more diagnostic information than mere descriptive demographic profiling.

Two distinct profiles of Web travel buyers, rookies and veterans, were discovered [7] and questions remain about whether rookies differ from veterans on personal characteristics. Various types of profiles emerge in these sorts of studies. From these, consumers can be categorized in terms of those relying primarily on affective or cognitive systems to evaluate vacation options with the use of an Online Decision Aid (ODA). The cognitive oriented traveler prefers a utilitarian approach designed to save time and money, for instance. An affective oriented traveler, on the other hand, could be a value-expressive individual who will use an ODA to save their profile information and generate a personalized vacation. Another affective oriented traveler, the Hedonic type, may find enjoyment using an ODA for 'vacation shopping'. Researchers studied the needs of consumers in online travel communities and the driving factors for their participation in an online community [8]. Some of the constructs developed were hedonic needs including amusement, fun, enjoyment, entertainment, and functional needs including information, efficiency, and convenience. These needs constructs proved valid for assessing travel community member needs.

Thus, there are numerous ways in which online consumers of travel products could be segmented. Any of the above methods could be used or novel approaches resulting from this study might be useful. Ultimately, the best approach is the one that most accurately describes consumers and enables a marketer to direct effective marketing programs at heterogeneous groups of consumers.

\section{THIS STUDY}

\section{A. Conceptual Framework}

The segmentation study was part of a larger one conducted by the writer that used the Theory of Reasoned Action (TRA) as part of its theoretical framework. Simply put, TRA proposes that a person's beliefs influence their attitudes which in turn affect their behavior as measured by behavioral intention. In the larger study, data was collected on specific travel products that survey respondents had booked in the past which were considered part of their prior experience with travel. Booking intention likelihood was assessed 
through logistic regression and it was found to be influenced by certain travel products that were booked previously. Logistic regression was used to generate inferences about the likelihood to book online based on key variables such as involvement, motivation, beliefs, and prior experience.

As in the research with online apparel purchases [9], TRA proposed by Fishbein and Ajzen [10] [11] and innovation adoption theory provided the core structure of the framework. TRA relies on behavioral intention which results from both attitudes toward a behavior and subjective norms toward that behavior. Subjective norms include the influence of people in one's social environment and the beliefs of people, weighted by the importance one gives to each of their opinions. The distinction between behavioral intention and behavior allows for explanation of limiting factors on attitudinal influence [11]. Some of these factors include attitude accessibility and issue involvement for example. Issue involvement is the relevance and salience of an issue or situation to an individual. Issue involvement has been correlated with both attitude access and attitude strength [12]. One key element of TRA is that behavioral intention has been found to predict actual behavior [10] [11].

Some modifications to this Framework were made to suit the unique dynamics of the travel product and the buying behavior of consumers. One of the primary considerations for instance, is the fact that most travel products are large ticket items usually requiring much thought, knowledge, and involvement so that consumers become engaged in a planning or researching process before buying or booking a travel product. Thus, information search and plans often take place before purchases. Participants in focus groups, interviews and case studies often raised this topic of the desire to research [13]. Another researcher uncovered a similar dynamic [14]. Thus, the Conceptual Framework incorporated the act of searching that sometimes precedes purchasing travel products.

The Framework helps the researcher evaluate how a consumer purchases a travel product with the assistance of an intelligent online decision aid (ODA). An ODA is sometimes nested within a travel website so that a consumer is unaware they are using a sophisticated tool. In this study an ODA is defined as - travel websites, consolidator such as Orbitz, online travel agency, travel search engines such as Kayak, and others on the IDS Intelligent tools can be found embedded in travel websites such as Farecast's airfare predictive analytics tool, which is now incorporated into Expedia's website infrastructure.

Insights from focus groups, personal interviews, case studies, guided the development of the Framework so that it was formulated using current literature and qualitative research conducted. The central process this research documents is the impact of various factors on the consumers' choice of online aids for travel purchases.

\section{B. Questionnaire}

An online survey questionnaire was used to determine how various factors affect travel planning and purchasing decisions. A total of 1300 respondents completed surveys. One hundred and two surveys were deleted, as responses were not complete. The survey was pre-tested after 250 surveys were collected. Thirty five questions were asked to assess prior experience with computers and the Internet, purchasing patterns online and offline, beliefs and attitudes about travel agents and travel websites, knowledge of travel and involvement with it, motivations for using the Internet, and various demographics.

Research questions of a demographic nature included what significant differences exist in terms of age, gender, education, occupation, or family income of those consumers who do and do not purchase leisure travel online?

In the dataset, females represented the largest gender of respondents, $63 \%$ compared to $37 \%$. Family income was quite evenly distributed. The dominant age groups were between 26 and 55 years of age. Almost $90 \%$ of respondents had a level of education beyond high school and the largest category had completed trade school, college, or a university degree.

\section{Statistical Tests}

Spearman correlation analysis and the Kruskal-Wallis test using SPSS 17.0 revealed insights on the demographic data that are useful for segmentation purposes. Demographic dimensions could be combined with other variables to target leisure travelers for marketing purposes [12]. Patterns of relationship between demographic variables and research variables are always of interest to marketers.

Relationships between age, education level, household income, and key variables are examined below.

\section{Hypotheses}

The following are the relevant hypotheses tested.

H1. Age is negatively related to intention to book leisure travel through the Internet.

$\mathrm{H} 2$. Level of education is positively related to intention to book travel through the Internet.

H3. Level of household income is positively related to intention to book travel through the Internet.

\section{Age AND ONLINE BOOKING INTENTION}

H1 Age is negatively related to intention to book travel through the Internet.

The relationship between age and online travel booking intention was investigated using Spearman's Rank Order Correlation. Age is negatively associated with intention to book travel through Internet but this association is negligible, rho $=-0.0286, \mathrm{n}=1142$. The hypothesis of independence cannot be rejected as the $p$-value $=0.3350>0.05$. To check if rho is significantly less than zero, we divide the $p$-value by 2 . So for a one tail test (left tail) the $p$-value $=0.1675$. This means there is no significant negative relationship between age and intention to book travel online. Therefore, hypothesis $\mathrm{H}_{1}$ is not supported.

Categories of online booking intention were merged so that three remain, $1=$ highly likely, $2=$ likely, and $3=$ somewhat likely. A Kruskal-Wallis test revealed there was a statistically significant difference in online booking intention levels across different age categories: under $18, \mathrm{n}=1: 18$ to $25, \mathrm{n}=137: 26$ to $35, \mathrm{n}=294: 36$ to $45, \mathrm{n}=302: 46$ to $55, \mathrm{n}=$ 270: 56 to $65, \mathrm{n}=119: 66$ to $70, \mathrm{n}=11$ : over $70, \mathrm{n}=8), \chi^{2}(7$, 
$\mathrm{n}=1142)=15.591, p=0.029$. The oldest age level recorded a higher median score $(\mathrm{Md}=3)$ than any other age level category, indicating a 'somewhat likely' intent to book online. A negative relationship between age and booking intention was anticipated. Spearman's correlation confirms such a relationship even though it is not statistically significant.

Fig. 1 plots the mean scores of online travel booking intention, and age graphically using all eight categories of age. In the levels of online travel booking intention a score of 1 means 'highly likely' and higher scores mean less likely. A sigmoidal or S-shaped relationship is clearly evident with females who represented the largest number of survey respondents. This pattern will influence the data that Spearman's correlation uses in its calculation. Intention to book travel online decreases beyond the age of 65 for both males and females.

\section{LEVEL Of EDUCATION AND ONLINE BOOKING INTENTION}

$\mathrm{H} 2$ Level of education is positively related to intention to book travel through the Internet.

The relationship between education and online booking intention was studied using Spearman's correlation. Education level is negatively associated with intention to book travel through the Internet, rho $=-0.1703, \mathrm{n}=1140$. The hypothesis of independence is rejected since the $p$-value $=0.0000<0.05$. Since the Spearman's rho is -0.1703 , it is significantly less than zero as the $p$-value for a left tail test will be less than the 0.05 level of significance. This means there is a significant negative relationship between level of education and intention to book travel online. Hypothesis $\mathrm{H}_{2}$ is not supported.

Categories of online booking intention were collapsed so that three remain, $1=$ highly likely, $2=$ likely, and $3=$ somewhat likely. A Kruskal-Wallis test revealed there was a statistically significant difference in online booking intention levels across different education categories (some grammar school, $\mathrm{n}=2$ : completed grammar school, $\mathrm{n}=3$ : some high school, $\mathrm{n}=22$ : completed high school, $\mathrm{n}=105$ : some trade school, college, or university, $\mathrm{n}=266$ : completed trade school, college, or university degree, $\mathrm{n}=545$ : graduate studies or masters degree, $\mathrm{n}=147$ : post graduate studies or advanced $\mathrm{PhD}$ degree, $\mathrm{n}=50), \chi^{2}(7, \mathrm{n}=1140)=40.522, p=$ 0.000 . The education level groups who have completed trade school, college, university and higher level qualifications recorded a lower median score $(\mathrm{Md}=1)$ than any other education level category, indicating 'highly likely' intent to book online. This seems to contradict Spearman's test results of hypothesis $\mathrm{H}_{2}$.

Fig. 2 plots the mean scores of online travel booking intention, as well as education graphically using eight category levels of education. A positive relationship is seen where booking intention increases with rising education levels. This supports the Kruskal-Wallis test results.

\section{HOUSEHOLD INCOME AND ONLINE BOOKING INTENTION}

H3 Level of household income is positively related to intention to book travel through the Internet.

Spearman's correlation was employed to evaluate the relationship between household income and online travel booking intention. Household income is negatively associated with intention to book travel online, rho $=-0.1340$, $\mathrm{n}=1138$. The hypothesis of independence is rejected as the $p$-value $=0.0000<0.05$. Because Spearman's rho is -0.1340 , it is significantly less than zero as the $p$-value for a left tail test will be less than 0.05 . This means there is a significant negative relationship between level of household income and intention to book travel through the Internet. Hypothesis $\mathrm{H}_{3}$ is not supported.

Categories of online booking intention were collapsed so that three remain, $1=$ highly likely, $2=$ likely, and $3=$ somewhat likely. The Kruskal-Wallis test conducted with the demographic of income and online booking intention revealed a statistically significant difference in online booking intention levels across different income groups (under $\$ 25,000, \mathrm{n}=50$ : $\$ 25,000$ to $\$ 49,999, \mathrm{n}=165$ : $\$ 50,000$ to $\$ 74,999, \mathrm{n}=227: \$ 75,000$ to $\$ 99,999, \mathrm{n}=183$ : $\$ 100,000$ to $\$ 149,999, \mathrm{n}=222: \$ 150,000$ or more, $\mathrm{n}=141$ : prefer not to answer, $\mathrm{n}=150), \chi^{2}(6, \mathrm{n}=1138)=44.622, p=$ 0.000 . The income group under $\$ 25,000$ recorded a higher median score $(\mathrm{Md}=3)$ than any other income group, indicating a 'somewhat likely' intent to book online, whereas, the higher income groups recorded a median score $(\mathrm{Md}=1)$ indicating 'highly likely' intent. Mid-level income groups $(\$ 25,000$ - \$74,999) had a median score $(\mathrm{Md}=2)$ showing a 'likely' intent to book online. These results were anticipated but they are not confirmed in hypothesis test $\mathrm{H}_{3}$. Even though Kruskal-Wallis suggests there is a statistically significant difference in online booking intention levels across different income groups, Spearman's Rank Correlation shows there is a significant negative or opposite relationship between level of household income and intention to book travel through the Internet so that hypothesis $\mathrm{H}_{3}$ was not supported.

Fig. 3 plots the mean scores of online travel booking intention, as well as the seven categories of income. A curvilinear relationship is clearly evident. Online travel booking intention becomes more likely with increasing annual household income until the income category of $\$ 100,000$ to $\$ 149,999$, and then the likelihood intent to book online reverses sharply. This could easily explain the conflicting results of Spearman's and the Kruskal-Wallis test.

\section{DATA ANALYSIS}

The results of Spearman's Rank Order Correlation hypothesis tests $\mathrm{H}_{1}, \mathrm{H}_{2}$, and $\mathrm{H}_{3}$ are rather puzzling when these results are compared with Kruskal-Wallis tests for most demographic variables. However, there may be reasonable explanations for this that the charts below imply.

It is natural to assume consumers who book travel online are younger and have a higher education and income. However, there appear to be demographic parameters within which marketers should focus their efforts. Higher income people may not book online as often as marketers believe. Wealthy people may feel their time is too valuable to spend 
hunting around the Internet for travel deals and so they call a travel agent and are willing to pay them for their effort. Fig. 3 suggests marketers should target people in a family income range no higher than between $\$ 100,000$ to $\$ 149,999$. It could be that above this range people call a travel agent. Since income and education are correlated, there could be an education level ceiling above which marketers should not target also. In this study, Spearman's correlation between education level and income is positive, rho $=0.1263, \mathrm{n}=$ $1143, p$-value $=0.0000<0.05$. Fig. 4 plots education level and the mean number of leisure trips taken in the past year. The number of trips forms a plateau at an intermediate education level - some trade school, college or university, and at the post-graduate studies level, the mean number of leisure trips decreases. Highly educated people could be time-starved and have less leisure time; as a result, they take fewer vacations and they may also want an agent to arrange their trip rather than spending time online. Fig. 1 suggests online travel marketers should target both male and female consumers up to the age of 65 . Non-bookers tend to be those aged 65 plus years and have a less 'wired' lifestyle. Perhaps older respondents are less likely to book online as the Internet is overwhelming to them so they rather call a travel agent.

Lastly, the questionnaire operationalized travel website usage with a single item asking, "How often do you visit a travel website to research or book a leisure travel product?" This is a similar volume segmentation variable as outlined in a study where researchers investigated travel agency usage [2]. Such volume segmentation may be meaningful in travel website usage especially when used in combination with key psychographic and demographic variables. Fig. 5 graphs education level and the mean number of times a respondent visited a travel website to research or book a travel product. There appears to be a gender difference at the higher education levels. When age and the mean number of times visited a travel website are plotted, above the age range of 56-65 there is also a gender difference in mean number of website visits.

\section{CONCLUSIONS AND MANAGERIAL IMPLICATIONS}

Demographics are likely to play an important role in predicting online behavior just as it does in traditional marketplaces. For instance, in a recent study respondents with school aged children found travel websites often unable to provide the information needed or allow booking to accommodate a family [13]. The requirement for multiple seats often means fewer flight options could be found online, for example. Using bed and breakfast establishments are desirable as they provide a home atmosphere that is more personal and secure when traveling with children than afforded by typical hotel facilities. As a result, travel agents are consulted to locate B \& B's and flights when traveling with family members.

Managers must be aware of the demographic and other predictors of future online travel purchase intention. Demographic variables of income and education could be useful bases for segmentation. Online leisure travel marketers should target both male and female consumers up to the age of 65 , those with a family income no higher than the range of $\$ 100,000$ to $\$ 149,999$, and those generally having higher education levels. In addition, Ref. [13] suggests using combined approaches of segmentation as the best way to identify and target online consumers of leisure travel products. This is because demographics as well as motivations, prior experience with the Internet, and other variables influence online booking intention of leisure travel products.

In the larger study referred to earlier, 14 socio and psychographic predictors were found to affect online booking intention using logistic regression. The regressed model revealed the following predictors: social acceptance having some friends and family who buy travel products on the Internet, a belief that booking with a travel agent is inconvenient, an attitude that booking with a travel website is positive, the number of leisure trips taken in a year, the amount of time spent each week on the Internet, information motivation - the Internet provides quick and easy access to large volumes of information, convenience motivation - the Internet being available anytime and anywhere, being involved with travel and travel planning and considering it important, using the Internet for a longer period of time, and feeling knowledgeable about travel products, destinations and travelling in general. Prior experience predictors included booking travel products online, specifically, destination tour/attraction tickets, hotels or accommodations, airline tickets, and long-distance train tickets.

In addition to uncovering these predictors, the probability of group membership in each category (online booking intention where, 1 = highly likely, 2 = likely, and $3=$ somewhat likely) was determined using logistic regression. When one combines these probabilities with the demographic parameters stated earlier, it gives a website operator valuable information for targeting consumers.

A similar sort of combination is advocated by another researcher who determined a predictive relationship exists between internet usefulness and the internally-driven values of travelers (e.g., self-fulfillment, excitement, fun and enjoyment). When this information is combined with demographic characteristics of internet users, it yields a more individualized picture of a market segment. Consequently, communication managers are better able to create more personalized messages that appeal to consumers' core beliefs and values [15].

As far as volume segmentation is concerned, logistic regression calculations imply that a consumer who has taken fewer than five leisure trips in the past year has a reduced probability, $52.12 \%$, of being 'highly likely' to book online compared to a consumer who took more than six leisure trips, $71.36 \%$. The probability increases from $71.36 \%$ to $75.4 \%$ when a consumer has been using the Internet longer (how long using Internet). The probability increases again to $78.8 \%$ when the length of time each week using the Internet is larger and to $98 \%$ probability when the customer has previously purchased long-distance train tickets.

Another researcher, using travel agencies, found that populations, segmented by usage, are different in both their identifiable psychographic and demographic characteristics 
[2]. Furthermore, there appears to be relevant industry-specific usage patterns so that segmentation by usage may vary from one industry to another. Research from Forrester and comScore for example, reveal that visitors to car websites behave differently than visitors to other e-commerce sites [16].

Thus, the travel sector, which has unique characteristics of its own, warrants continued examination by researchers since these attributes could impact usage. Segmentation approaches outlined in this article could help marketers identify and target online leisure travel bookers in this important industry.

\section{REFERENCES}

[1] Wyner, G. (1995), Segmentation analysis, then and now. Marketing Research, 7 (1), 40-41.

[2] Goldsmith, R., \& Litvin, S. (1999). Heavy users of travel agents: A segmentation analysis of vacation travelers. Journal of Travel Research, 38(2), 127.

[3] Mo, C., Howard, D. R., \& Havitz, M. E. (1993). Testing an international tourist role typology. Annals of Tourism Research, 20, $319-335$.

[4] Cohen, E. (1972). Towards a sociology of international tourism. Social Research, 39, (1),164-182.

[5] Shoemaker, S. (1994). Segmenting the US travel market according to benefits realized. Journal of Travel Research, 32(3), 8.

[6] Bhatnagar, A. \& Ghose, S. (2002). A latent class segmentation analysis of e-shoppers. Journal of Business Research, 5748, 1-10.

[7] Forrester Research. (2001). [On-line]. www.forrester.com.

[8] Wang, Y., \& Fesenmaier, D. (2004). Modeling participation in an online travel community. Journal of Travel Research, 42, $261-270$.

[9] Yoh, E. (1999).Consumer adoption of the Internet for apparel shopping (Doctoral dissertation, Iowa State University, 1999). Dissertations Abstracts International, 13.

[10] Fishbein, M., \& Ajzen,I., (1975). Beliefs, Attitude, Intention, and Behavior: An Introduction to Theory and Research, Reading, MA: Addison-Wesley.

[11] Ajzen, I., \& Fishbein, M. (1980). Understanding Attitudes and Predicting Social Behavior. Englewood Cliffs, NJ: Prentice-Hall.

[12] Zaichkowsky, J. L. (1985). Measuring the involvement construct. The Journal of Consumer Research, 12(3), 341-352.

[13] Conyette, M.H. (2010). Determinants of online leisure travel planning decision processes: A segmented approach. Unpublished doctoral dissertation, University of Newcastle, Newcastle upon Tyne, UK.

[14] Hyde, K.F. (2008). Tourist information processing and touring planning theory. Unpublished manuscript.

[15] Fall, L.(2005). What Kinds of Vacation Travelers Are Surfing the Net? A Market Segmentation Study. Journal of Website Promotion, 1(3), 75-97.

[16] Forrester Research. (2010). [On-line]. www.forrester.com.
DEMOGRAPHIC ANALYSIS CHARTS

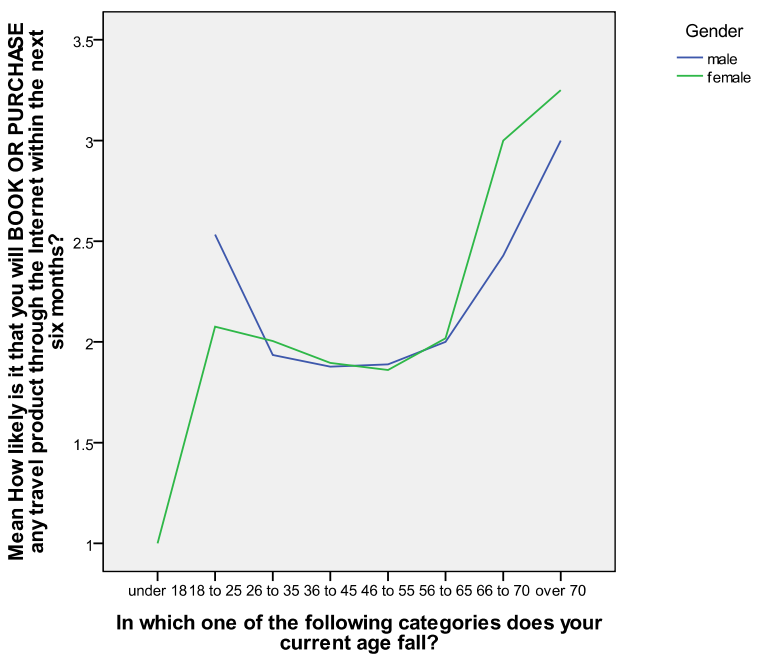

Figure 1. Age and Mean Scores of Online Travel Booking Intention

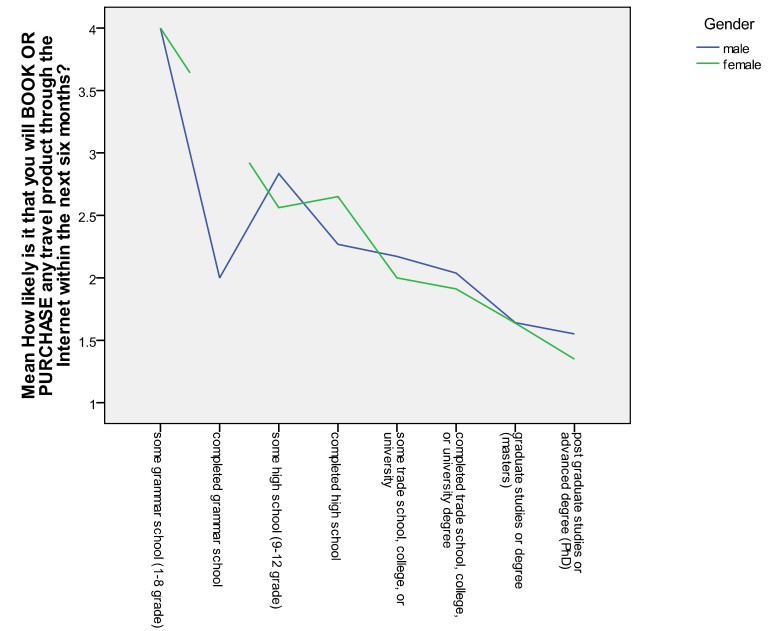

Figure 2. Education and Mean Scores of Online Travel Booking Intention

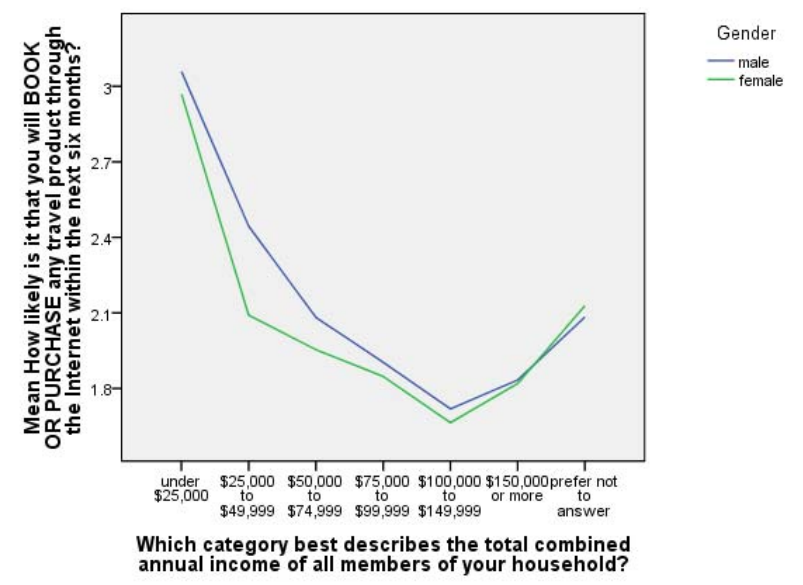

Figure 3. Income and Mean Scores of Online Travel Booking Intention 
International Journal of Trade, Economics and Finance, Vol.2, No.1, February, 2011 2010-023X

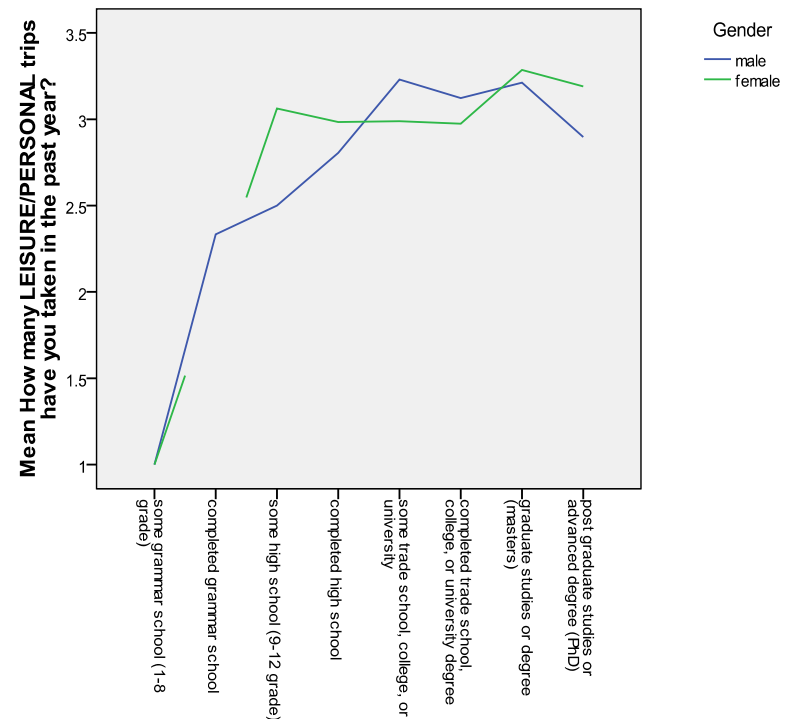

Figure 4. Education Level and Mean Number Leisure Trips Taken in Past Year

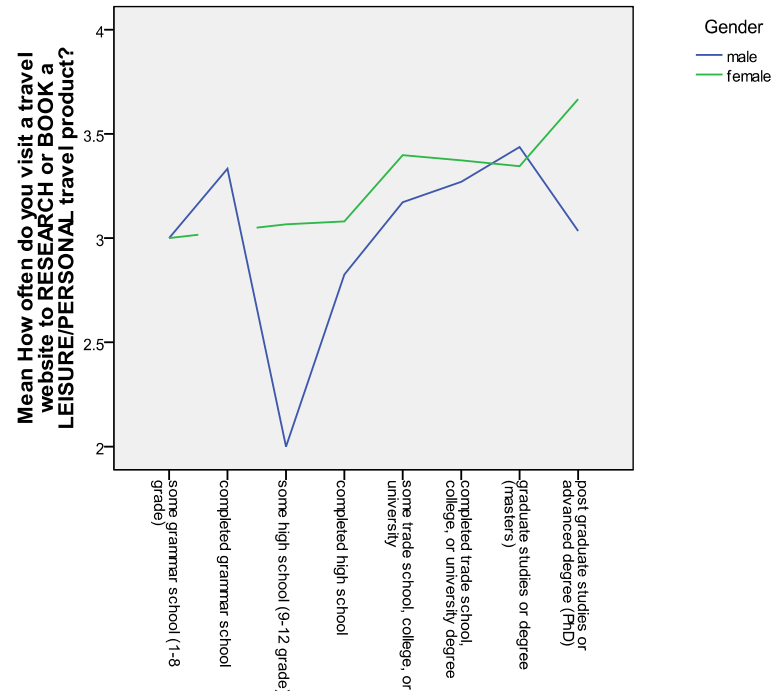

Figure 5. Education Level and Mean Number of Times Visiting a Travel Website 